\title{
Advancements in Methods Used for Identification of Lichens
}

\author{
Sachin Singh ${ }^{1}$, Mamta Arya ${ }^{2 *}$ and Shailesh Kumar Vishwakarma ${ }^{3}$ \\ Department of Zoology and Biotechnology, H.N.B. Garhwal Unviersity, \\ Uttarakhand-246174, India \\ *Corresponding author
}

\begin{abstract}
A B S T R A C T
\end{abstract}

\begin{tabular}{|c|c|}
\hline & Lichen is a combination of two organisms one is alga and another one is fungus. There is \\
\hline Keywords & $\begin{array}{l}\text { organism and the fungus part provides structural support to the organism. Lichens has been } \\
\text { used for many purposes in all over the world because lichens have tremendous properties in }\end{array}$ \\
\hline Lichens, & them due to the presence of various natural compounds known as primary and secondary \\
\hline Chemotyping, DNA & $\begin{array}{l}\text { metabolites which are not known to other group of plants (unique with respect to nigner plants), } \\
\text { to take the benefit of these properties correct identification of lichens is necessary. }\end{array}$ \\
\hline $\begin{array}{l}\text { Barcoding, PCR } \\
\text { Genotyping }\end{array}$ & Identification of lichen is very difficult task due to the complex structure of lichens, which \\
\hline Article Info & identified correctly, properly, easily and on time. Different types of methods are used to \\
\hline $\begin{array}{l}\text { Accepted: } \\
12 \text { July } 2019 \\
\text { Available Online: } \\
10 \text { August } 2019\end{array}$ & $\begin{array}{l}\text { mainly use three different approaches for identification of lichens (a) Microscopic approaches } \\
\text { (b) chemical approaches (c) Molecular approaches. Molecular approaches are the best and } \\
\text { fastest approaches to identify the lichens correctly and easily. With the help of information } \\
\text { technology and computer applications all the informative data which is collected during }\end{array}$ \\
\hline & $\begin{array}{l}\text { identification is compiled and stored in an application in the form of digital library through } \\
\text { which one can easily retrieved the data for future use. This helps the taxonomists in } \\
\text { identification, characterization and in quick classification of lichens. }\end{array}$ \\
\hline
\end{tabular}

\section{Introduction}

The word "lichen" was termed by Theophrastus (Father of botany) in 300 BC. It is a Greek word which means superficial growth on the bark of the trees. Lichen is a combination of two organisms one is alga and another one is fungus, sometimes in place of alga, cyanobacteria (blue green algae) is also present (Stace, 1991). Alga and fungus helps each other in surviving, the algal part is known as photobiont as it contain photo synthetic pigment which provide food for the whole organism with the help of sunlight and other part is known as mycobiont (myco=fungus) this provides structural support to the organisms (Stace, 1991). The relationship between the two organisms' alga and fungi proven later. There were lots of controversies about the relationship between alga and fungus. For the first time a Swiss botanist Schwendener in 1867demonstrated the dual nature of lichen thallus (presence of both algae and fungus) after this there is a great discussion started on the nature of relation between the fungus and the algae. It 
was proposed that the nature is parasitism because of the haustarium of fungus enter in the algae and draw out nutrients for its growth, but later this theory was discarded because in parasitism the organism which is dominant kill the weaker one but in this case the algae does not die. Then this is called helostism because in helostism master and slave relationship is appears and in this case fungus is the master and the algae is slave, some scientists called it endosaprophytes because fungus is saprophyte (which feeds on dead and decade organisms) it is observed in some lichen thallus the algae is dead and the fungus feed on them (Stace, 1991).

Some lichenologist called the relationship mutualism in which both the organisms help each other without any harm and in lichen alga provide food and nutrition for growth and fungus provide protection and structural support to the whole organism, therefore relation is called symbiotic in which two organisms living together without killing each other (Ahmadjian, 1995). Lichen is very complicated organism, mostly it contains $90 \%$ of fungus and the remaining is the alga, this ratio can be varying from species to species.

\section{Types of lichens}

Lichens are the organisms which grow in diverse condition and at all phytological regions of the world (Boustie and Grube, 2005). Their growth is very slow, they grow few millimeters or centimeters in a year (Table 1).

Lichens are categorized in different types on the basis of their size, substrate in which they grow and on the basis of their growth forms.

\section{On the basis of size}

On the basis of size lichens are of two types: Microlichens and Macrolichens (Awasthi, 1988; 1991; 2007).

\section{Microlichens}

These are the lichens which are small in size and are not easily defined because their physical characters cannot be seen easily without microscope by naked eyes.

\section{Macrolichens}

These are the lichens which are well defined and can easily observe by naked eyes.

\section{On the basis of substrate on which they grow}

Lichens which are grow on bark of the trees are called corticolous, which grows on twigs called ramicolous, which grows on dead wood logs are called legnicolous, which grows on rock and boulders are called saxicolous, grows on moss called musicolous, grows on soil called terricolous and on evergreen leaves called follicolous. They are also growing under water but not only in water or in ice, they always required substrate for growth (Mishra et al., 2016).

\section{On the basis of growth forms}

On the basis of physical appearance lichens are of three types.

\section{Crustose}

These are the lichens in which thallus is closely attached to the substratum without leaving any free margin and it is very difficult to collect it. Most of the times these lichens are collected along with its substrate, in these lichens rihzines and the lower cortex is absent.

\section{Foliose}

These are the lichens in which thallus is loosely attached to the substratum leaving free margins, they appears like a leaf and therefore also called leafy lichens. 


\section{Fruiticose}

These are the lichen in which the thallus is attached only at one point and the rest of the thallus growing hanging and erect like a fruit and therefore they are called fruiticose lichens.

\section{Importance of identification of lichens}

Lichens has been used for many purposes in India as well as in all over the world because lichens have tremendous properties in them due to the presence of various natural compounds known as primary and secondary metabolites they have varied chemistry and produced many polyketide derived phenolic compounds such as depsides and depsidones which are not known to other group of plants (unique with respect to higher plants), therefore lichens are used for the preparation of natural dyes, crude drugs for medicines, perfumery, agrochemicals(Banerjee, 2002; Kumar and Upreti, 2008), also evaluate air quality, climate change, to detect accumulation of heavy metals. Lichens are the most significant indicators of air pollution and ecosystem health (Richardson, 1992; Upreti and Pandev, 1994; Wolseley et al., 1994; Upreti, 1995; Sloof, 1995; Mistry, 1998; Vokou et al., 1999). Many lichens have economic applications, including uses in traditional medicines (Richardson, 1991; Gonzalez-Tejero et al., 1995; Upreti, 1994; Upreti and Negi, 1996; Negi and Kareem, 1996), these properties makes lichens very popular among the scientists for future research, to take the benefit of these properties correct identification of lichens is necessary because these properties are specific for specific species. There are many properties which are not explored yet because of identification, which is very difficult task due to the complex structure of lichens which consumes lot of time. Lichens are very interesting organisms as they contain huge properties and most of them are left untouched. Exploration of these properties is only possible when lichens are identified correctly, properly, easily and on time.

\section{Methods used for identification of lichens}

Lichens contain two organisms together (alga and fungi), both the organisms have different species of alga and fungi in different ratio. Lichens are very sensitive to environment and geographical conditions therefore their properties are changed according to the environment in which they found due to this, clear and correct identification of lichens is very difficult, thus the taxonomist used different methods for the identification of lichens, these methods were used from so many years and are modified day by day to get more information or knowledge about lichens.

\section{Microscopic approaches}

Microscopic methods are used to identify morphology and anatomy of lichens. Study of lichen morphology began with the work of Erik Acharius who is regarded as father of lichenology. Study on lichen structures began over a century ago when the light microscope became readily available. By 1860 , Schwendener was able to present an accurate account of the internal structure of several fruticose lichens(Parizadeh et al., 2017). Lichens were identified based on the morphology and anatomy of thallus structure and their mode of reproduction with the help of available literature of Awasthi, 1988, 1991, 2000 and 2007; Nayaka, 2004; Upreti and Divakar, 2005and Upreti et al., 2008 and also by using available standard keys by Awasthi, 1988, 1991, 2000; Goward et al., 1994; Malcolm and Galloway, 1997; McCarthy and Malcolm, 2004. Keys to Lichens of North America by Brodo and Sharnoff, 2001; Macrolichens of the Pacific Northwest by McCune and Geiser (1997), key to the genera of Australian macrolichens by McCarthy and 
Malcolm, 2004, Lichen flora of the United States by Fink B., 1935and most important lichen key books in India: A key to the Macrolichens of India and Nepal by Awasthi (1988), A key to michrolichens of India, Nepal and Sri Lanka by Awasthi (1991) and A Compendium of the Macrolichens from India, Nepal and Sri Lanka by Awasthi (2007) are widely used for identification. Some online keys like website of Botanischer Garten under Botanisches Museum, Germany were also used.

There are different characters present on the surface and inside the thallus of lichens; these characters were observed during identification of lichens. The morphological and anatomical characters are varying from genus to genus.

\section{Morphology}

While doing morphology the outer most surface was observed, the upper surface and the lower surface of lichen thallus were observed deeply under dissection microscope. The morphological characters are divided into two parts, characters of thallus and characters of fruiting bodies, firstly the thallus were grouped according to their growth forms (leprose, crustose, foliose, squamulose, dimorphic, fruiticose), thallus shape (irregular, circular), size, color, texture (smooth, rough, warty), upper surface is observed for the presence of finger like projections (isidia), granular structure (soredia), fine powder (pruina), black dots (pycnidia) and whitish decorticated areas (pseudocyphellae). The branching pattern length and breadth of marginal lobes, presence of hair like structure (cilia) has to be noted. The morphology of fruiting bodies has to be studied separately. In case of apothecia, shape (rounded or stretched), size, attachment (stalked or not) color and texture of the margin and disc, shape of the disc (concave or convex) are observed. In case of perithecia its color, shape, size and the position of its opening (ostiole, apical or lateral); single or grouped has to be noted. The lower surface of only foliose lichens can be seen as it is absent in crustose lichens. While dimorphic and fruticose lichens do not show dorsiventral differentiation. The color of lower surface, presence of any pores (cyphaellae, pseudocyphellae), presence or absence of rihizines (root like structure) their color, distribution, branching, abundance are to be noted. Lichens are also observed inside a closed UV chamber at 254 and $365 \mathrm{~nm}$ to see whether the lichen has florescence characteristic (yellowish and bluish color) or not because some lichens shows florescence due to the presence of substance called lichexanthone.

\section{Anatomy}

While doing anatomy the internal structure of the thallus were observed by cutting a vertical thin layer of thallus, a slide was prepared and observed under compound microscope with minium magnification of 40x. The anatomy of the thallus is done to see the thickness of various layers (upper cortex, algal layer, medulla, and lower cortex), types of algae and their distribution (stratified- heteromerous or uniform- homomerous) and arrangement of fungal hyphae (vertical or horizontal) with in the thallus. To know about the algal layer, lichen thallus was exposed by scraping the upper cortex with blade and algal part which appears (dark green, blue green, black) is picked up and examined under microscope.

The anatomical characters of fruiting bodies (ascocarp) are very important especially in case of crustose lichens. Types of spore (simple, septate), color (hyaline, brown), their shape, size, number of spores in a spore sac (ascus), color of ascocarp wall (exciple), presence or absence of crystals and algal cells in the wall, color and height of different layers (hymenium, epi and sub hymenium, 
hypothecium) with in the theascocarps are to be noted. The branching pattern and arrangement of paraphyces shape and color of apical cell are important character to be noted. The morphology of the taxa was studied using a stereo binocular microscope. The details of thallus anatomy and fruiting bodies were studied by compound microscope (Mishra et al., 2016).

\section{Chemical approaches}

Chemistry of lichens is done to know about the chemical composition of lichens which plays a vital role in classification and identification of lichens, because sometimes organisms which are morphologically and anatomically same have different chemical composition due to minor genetic and epigenetic changes. The method by which all chemical properties of a sample are identified is known as chemotyping and the classification done according to the presence of chemicals is known as chemotaxonomy. The first chemical tests conducted on lichen thalli for taxonomic purposes were carried out by Nylander in $1860 \mathrm{~s}^{33}$. He detected the presence of various lichen substances by spotting chemical reagents directly on the lichen thallus (spot tests) to produce characteristic colour changes: iodine solution (I; blue with certain polysaccharides), potassium hydroxide solution $(\mathrm{K}$; distinctive colours with quinones, some depsides and depsidones) and calcium hypochlorite solution (C; pink or red with some depsides) (Elix, 2104). Furthertest reagents followed: KC (K solution followed by C) and CK (with reverse addition). Nylanderutilised the characteristic medullary and cortical reactions as a specific character, but the origin of these characteristic colour reactions remained unknown, these reactions are quick and inexpensive way to screen lichen substances and to help identification of lichen species. Four tests are routinely used in lichenology: the $\mathrm{C}, \mathrm{K}, \mathrm{KC}$ discovered by Nylander (1866) and the PD test introduced by Asahina (1934). The first serious chemical investigations were conducted by Zopf, culminating in his publication of 'Die Flechtenstoffe' in 1907 with the description of over 150 lichen compounds (Elix, 2104). However, the ultimate structural elucidation of many common lichen metabolites came from to the meticulous pioneering work of Asahina and co-workers in Japan in the 1930s (Asahina and Shibata, 1954). This laid the foundation for further research on these compounds. More recent workers in this field have included Huneck in Germany, C. F. and W. L. Culberson in the USA, Tabacchi in Switzerland, Elix and co-workers in Australia, Wilkins in New Zealand and Garbarino and colleagues in Chile Huneck\& Yoshimura, 1996). Normal methods of organic structure determination are utilized, but the development of $13 \mathrm{C}$ and $1 \mathrm{H}$ NMR spectroscopy, mass spectrometry and X-ray crystallography have greatly aided structural studies. However, from the point view of most lichenologists, the development of microchemical detection methods has been far more important. Asahina developed an additional spot test reagent $(\mathrm{P}$ or $\mathrm{PD}$, an alcoholic solution of $p$-phenylenediamine) and, more importantly, a microcrystallization technique for more definitive recognition of individual lichen acids on a routine basis. This involved extraction of a lichen fragment with acetone; evaporation of the solvent and recrystallization of the remaining residue from a suitable solvent - all conducted on a microscope slide. A particular lichen substance crystallized in a distinctive shape and colour and was identified by comparison with photographs of authentic materials. This method has been superseded by more accurate and sensitive chromatographic methods (Elix, 2104). Subsequently, the techniques of paper chromatography and, particularly, thin layer chromatography (TLC) have greatly improved 
the speed and certainty of recognition of lichen substances by means that are simple to use and relatively inexpensive. Two dimensional TLC has considerably improved RF discrimination of structurally similar compounds and has enabled the identification of minor constituents present in complex mixtures (Culberson and Johnson, 1976). Standardized methodology and further refinements of analytical TLC procedures for detecting and comparing lichen metabolites have been reported by C. F. Culberson and colleagues (Culberson and Ammann, 1979; Culberson and Johnson 1981; Culberson and Johnson 1982). More recently still, high performance liquid chromatography (HPLC) also has been employed as an effective analytical tool for the separation and identification of lichen substances. An added advantage of this technique is that it yields quantitative information about the components present in the total lichen extracts. At present, a disadvantage of the HPLC system is the expense of the equipment and purified solvents, placing it beyond the reach of more modest institutions and routine chemotaxonomic investigations. Consequently, TLC remains the most readily accessible and widely used method for identifying lichen metabolites routinely. As chemical investigations now form an integral part of all serious taxonomic studies on lichenforming fungi, inevitably even the more experienced lichenologist encounters TLC spots that are unfamiliar and difficult to identify (Elix, 2104). In an effort to make most of literature information on standardized TLC, RF values and spot colour characteristics more readily accessible, and to keep such a library of information current as many more lichen metabolites are identified and characterized, databases suitable for storing such information have been prepared. The data has been manipulated on the computer by search programs Mactabolites (Elix et al., 1987); Wintabolites: (Mietzsch et al., 1993), which operates on experimentally observed RF values and TLC spot characteristics to search the database and generate a list of possible identities for the observed spot.

Table.1 Types of lichens

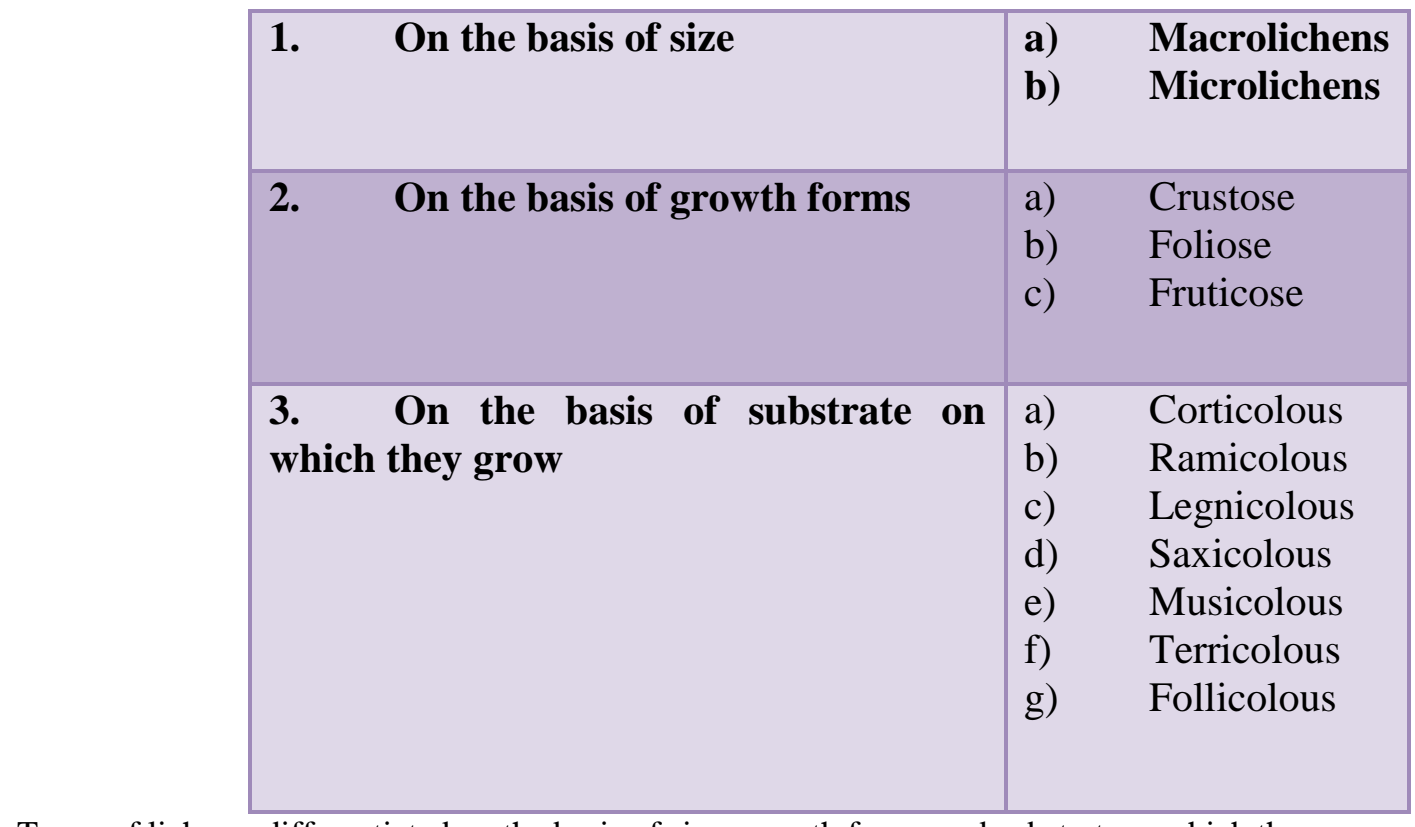

Types of lichens, differentiated on the basis of size, growth forms and substrate onwhich they grow. 
Table.2 Methods used for identification of lichens

\begin{tabular}{|ll|ll|}
\hline 1. & Microscopic Approaches & a) & Morphology \\
& & b) & Anatomy \\
\hline $\begin{array}{l}\text { 2. } \\
\text { (chemotyping) }\end{array}$ & Approaches & a) & Color spot test \\
& & b) & TLC \\
& c) & HPTLC \\
& d) & HPLC \\
\hline 3. Molecular Approaches & a) & PCR genotyping \\
& & b) & DNA Barcoding \\
\hline
\end{tabular}

Three major approaches are used for the identification of lichens, Microscopic approaches are based on physical characters of lichens, Chemical approaches exploit the chemical compounds of lichens to identify them while advanced molecular approaches used to identifying lichens on the basis of their genetic make-up.

\section{Molecular approaches}

To get more valuable, reliable and accurate information, the molecular approaches are the best methods for identification of lichens because in these methods genes which are responsible for all the physical characters and chemical compositions of organisms are studied in detail. With the development of DNA sequencing methods and the discovery of the polymerase chain reaction (PCR) for DNA amplification, biological systematics has increasingly been based on DNA sequence analysis. DNA based identification systems use standardized molecular biology techniques (DNA extraction, PCR and DNA sequencing) that can increase the speed of the identification of an unknown organism (Seifert et al., 2007). The development of DNA-based molecular biology allowed the cloning of genes encoding enzymes for natural product biosynthesis, first from fungi in the late 1980s and then from plants in the early 1990s (Desjardins, 2008). With the discovery of genes for biosynthesis of natural products, chemistry and genetics have entered a new interrelationship. Whereas previously natural product profiles were used to predict genetic relationships between organisms, now gene sequences can potentially be used to predict natural product profiles of plants or cultured microbes or perhaps even in food or agricultural samples (Desjardins, 2008). PCR genotyping is a technique by which natural products present inside an organism, are predicted with the help of PCR and DNA Sequencing. Molecular biologists in this field are becoming interested in developing and promoting PCR genotyping for research and commercial applications; some view PCR genotyping methods as less expensive replacements for traditional chemical analysis (Harjes, 2008). Development of PCR genotyping for predicting chemotypes will require collaboration between molecular biologists and natural product chemists, as well as community standards for reporting data (Desjardins, 2008) (Table 2).

Lichens are complex organisms their perfect identification is sometimes becomes critical for taxonomists. As lichens contain fungus mostly in large amount then the alga so, the classification of lichens is done on the basis of the fungus present inside the lichen thallus. The use of DNA sequence variation in fungal evolutionary studies started soon after molecular markers began to be used as tools for assessing relationships between organisms in the early 1970s (Dutta and Ojha, 1972) Walker and Doolittle (1982) were the first to use $5 \mathrm{~S}$ rRNA gene sequences to analyze the relationships among diverse groups of fungi (xu, 2016). However, it was not until the early 
1990s that DNA sequences began to be widely used in fungal evolutionary and population genetic studies (Xu, 2016). The initial adoption of molecular sequences in fungal studies was driven largely by developments in PCR and DNA sequencing technologies as well as the development of a set of fungal DNA primers by White et al., 1990. The paper by White et al., 1990 has been cited over 11, 000 times, and many of the primers, including the almost universal fungal ITS primers ITS1 and ITS4 are still widely used today (xu, 2016). By the mid1990s, PCR and DNA sequencing were becoming routinely used in biology laboratories, including for fungal strain and species identifications. These developments have contributed to the rapid expansion of fungal DNA sequences of several DNA fragments of the ribosomal RNA gene cluster to public databases. Over the last decade the field of DNA barcoding has emerged as a molecular method for species identification. DNA barcoding relies on a uniform region of the mitochondrial gene being amplified, sequenced, and analyzed by comparison to an open access database. Using molecular taxonomy to create a biological barcode that identifies organisms is the central goal of DNA barcoding, as well as creating a standardized reference library for the DNA based identification of target species. There are two central principals of DNA barcoding: standardization of the PCR methods and protocols, and the ability to grow the data as the science progresses (Hollingsworth et al., 2011). DNA barcoding can correct field misidentification, reduces ambiguity of species identification, makes species identification more exact, democratizes access by creating open access databases, and expands technical expertise of taxonomists (Stoeckle et al., 2004). The precise identification of organisms has been the realm of taxonomic experts who use specialized language and literature to describe and identify an organism. The goal of scientists who perform DNA barcoding is to create a library of every organism on earth (Stoeckle et al., 2004). DNA barcoding is a powerful tool for specimen identification that could potentially be applied for identifying and recognizing all fungi and overcoming the different sets of traditional criteria used for describing different groups of fungi. In 2012, the international Fungal Barcoding Consortium formally recommended that the internal transcribed spacer (ITS) regions of the nuclear ribosomal RNA gene cluster be used as the primary fungal barcode (Schoch $e t$ al., 2012). In fungi, the entire ITS region is about 600bp long and contains two variable spacers ITS-1 and ITS-2 that are separated by the highly conserved 5.8S rRNA gene (White et al., 1990). DNA Barcoding is used to identify the lichens correctly and accurately from a decade. The lichen forming fungi is used to generate DNA Barcode. The ITS region is sequenced and converted in the form of barcodes with the help of various barcoding software and these barcodes are then stored in publically accessible databases such as NCBI and BOLD for future use.

Lichens are found widely in all over the world and are used for various purposes such as for medicine, natural dyes production, perfume, fodder for animals, also helps in increasing soil fertility, used for environment monitoring etc. This is because it contains different types of natural compounds which are specific for specific species and are not known to other group of plants. To avail all the properties of lichens correct, accurate and on time identification is necessary or invention of a fast and reliable process of identification of lichens is necessary. There are lots of lichen identification methods invented by scientists because lichen is a complex organism and its identification is not an easy task there are lots of hindrances in identification of lichens because lichens are changed their chemical 
composition according to their geographical conditions to adapt the environment due to which their morphology and anatomy is same but the chemical composition is changed so the advanced method is used to differentiate and characterized these types of lichens and the method is called chemotyping in which the chemical composition of various lichens are to be found by various methods such as color spot test, TLC, HPTLC, and HPLC. In these methods color spot test is preliminary test which gives only primary information and TLC is the best one because other methods are expensive then TLC and TLC gives same and reliable result as others gives but the standard list of spots and their RF values has been not developed yet because as we know lichens change their chemical compositions to adapt the environment due to which RF values and the chemical properties vary within the same species from different locations. Some other methods are used to know the structure of the chemicals and the structures of different cells such methods are micro crystallography, NMR spectroscopy, mass spectroscopy, $\mathrm{x}$-ray crystallography etc. There is advancement in method of identification according to the requirements day by day. The molecular methods are most advanced methods and they are more accurate than others because in these methods the genetic variation is the parameter to differentiate the organisms and as we know the gene of an organism contains all the necessary, correct and accurate information about the organisms. Therefore from a decade lichens are identified by molecular methods DNA Barcoding is one of them in which DNA extraction, PCR amplification, specific gene sequencing (in case of lichen ITS region of mitochondrial gene) is done with the help of sequencer and at last the sequence is converted into the form of barcode with the help of software and stored in public database such as NCBI and BOLD so that one can retrieve the sequence from database for future research. All the valuable data of an organism can also be stored in the form of digital library and applications such as "picture this" can be created and easily used by a person to get information about any plant simply by clicking the photo of unknown plant. By uploading the picture of a plant in this application, results almost all the possible and nearest out comes (all about the plant- photos, its classification and other information). This kind of approach should also be used for lichens to overcome the expense and consumption of time in identification of lichens.

\section{References}

Ahmadjian, V. (1995). Lichens are more important than you think. BioScience, 45(3), 124.

Asahina, Y., and Shibata, S. (1954). Chemistry of lichen substances, Japan Society for the Promotion of Science. Tokyo, Japón.

Awasthi, D. D. (1988). Key to the macrolichens of India and Nepal. Journal of the Hattori Botanical Laboratory.

Awasthi, D. D. (1991). A key to the microlichens of India, Nepal and Sri Lanka.

Awasthi, D. D. (2000). Lichenology in Indian subcontinent. Bishen Singh Mahendra Pal Singh.

Awasthi, D. D. (2007). Compendium of the Macrolichens from India, Nepal and Sri Lanka. Bishen Singh Mahendra Pal Singh.

Banerjee, L. K. (2002). Diversity of coastal plant communities in India. ENVIS and EMCBTAP-Botanical Survey of India, Ministry of Environment and Forests.

Boustie, J., and Grube, M. (2005). Lichens-a promising source of bioactive secondary metabolites. Plant Genetic Resources, 3(2), 273-287.

Brodo, I. M., Sharnoff, S. D.,and Sharnoff, S. (2001). Lichens of North America. Yale University Press.

Culberson, C. F., and Johnson, A. (1976). A standardized two-dimensional thin-layer chromatographic method for lichen 
products. Journal of Chromatography A, 128(2), 253-259.

Culberson, C. F., and Johnson, A. (1982). Substitution of methyl tert.-butyl ether for diethyl ether in the standardized thin-layer chromatographic method for lichen products. Journal of Chromatography A, 238(2), 483-487.

Culberson, C. F., and Ammann, K. (1979). Standard method zurdünnschichtchromatographie von flechtensubstanzen. Herzogia, 5(1), 24.

Culberson, C. F., Culberson, W. L., and Johnson, A. (1981). A standardized TLC analysis of $\beta$-orcinoldepsidones. Bryologist, 16-29.

Desjardins, A. E. (2008). Natural product chemistry meets genetics: when is a genotype a chemotype? Journal of agricultural and food chemistry, 56(17), 7587-7592.

Dutta, S. K.,and Ojha, M. (1972). Relatedness between major taxonomic groups of fungi based on the measurement of DNA nucleotide sequence homology. Molecular and General Genetics MGG, 114(3), 232240.

Elix, J. A. (2014). A catalogue of standardized chromatographic data and biosynthetic relationships for lichen substances. Canberra: The Author.

Elix, J. A., Johnston, J., and Parker, J. L. (1987). Mactabolites. User's Manual. 2nd edn. Canberra.

Fink, B., and Hedrick, J. (1935). Lichen flora of the United States.

Gonzalez-Tejero, M. R., Martinez-Lirola, M. J., Casares-Porcel, M.,and Molero-Mesa, J. (1995). Three lichens used in popular medicine in Eastern Andalucia (Spain). Economic Botany, 49(1), 96-98.

Goward, T., McCune, B., and Meidinger, D. (1994). The Lichens of British Columbia. Illustrated keys. Part, 1, 1-181.

Harjes, C. E., Rocheford, T. R., Bai, L., Brutnell, T. P., Kandianis, C. B., Sowinski, S. G.,... and Yan, J. (2008). Natural genetic variation in lycopene epsilon cyclase tapped for maize biofortification. Science, 319(5861), 330-333.

Hebert, P. D., Stoeckle, M. Y., Zemlak, T. S., and Francis, C. M. (2004). Identification of birds through DNA barcodes. PLoS biology, 2(10), e312.

Hollingsworth, P. M., Graham, S. W., and Little, D. P. (2011). Choosing and using a plant DNA barcode. PloS one, 6(5), e19254.

Huneck, S., and Yoshimura, I. (1996). Identification of lichen substances. In Identification of lichen substances (pp. 11-123). Springer, Berlin, Heidelberg.

Kumar, B., and Upreti, D. K. (2008). An account of lichens on fallen twigs of three Quercus species in Chopta forest of Garhwal Himalayas, India. Annals of Forestry, 15(1), 92-98.

Malcolm, W. M. (1997). New Zealand lichens: checklist, key, and glossary. Museum of New Zealand Te Papa Tongarewa.

McCarthy, P. M. (2004). Catalogue of the lichen family Porinaceae. Mycotaxon, 89(1).

McCune, B., and Geiser, L. (1997). Macrolichens of the Pacific Northwest. USDA Forest Service.

Mietzsch, E., Lumbsch, H. T., and Elix, J. A. (1993). A new computer program for the identification on lichen substances. Mycotaxon (USA).

Mishra, G. K.,and Upreti, D. K. (2016). Diversity and distribution of macro-lichen in Kumaun Himalaya, Uttarakhand. International Journal of Advanced Research, 4(2), 912925.

Mistry, J. (1998). A preliminary lichen fire history (LFH) key for the cerrado of the Distrito Federal, central Brazil. Journal of Biogeography, 443-452.

Nayaka, S., Upreti, D. K., Phatak, S., and Samuel, C. (2004). Lichens of Bondla and Bhagwan Mahavir Wildlife Sanctuaries, Goa. Biological Memoirs, 30(2), 115-119.

Negi, H. R., and Kareem, A. (1996). Lichens: The unsung heroes. Amrut, 1, 3-6.

Nylander, M. W. (1866). Les lichens du Jardin du Luxembourg. Bulletin de la Sociétébotanique de France, 13(7), 364371.

Parizadeh H, Garampalli RH. (2017) Physiological and chemical analysis for identification of some lichen extracts. Journal of Pharmacognosy and Phytochemistry, 6(5):2611-21. 
Richardson D H S. (1991) Lichens and Man; in Frontiers in mycology (ed.) D L Hawksworth (Regensburg: CAB International), pp 187-210.

Richardson, D. H. (1992). Pollution monitoring with lichens. Richmond Pub. Co..

Schoch, C. L., Seifert, K. A., Huhndorf, S., Robert, V., Spouge, J. L., Levesque, C. A.,...\& Fungal Barcoding Consortium. (2012). Nuclear ribosomal internal transcribed spacer (ITS) region as a universal DNA barcode marker for Fungi. Proceedings of the National Academy of Sciences, 109(16), 6241-6246.

Schwendener, S. (1867). Report on Schwendener's announcement of the dual nature of lichens. Verhandlungen der Schweizerischen Naturforschenden Gesellschaft, Rheinfelden, 51, 88-89.

Seifert, K. A., Samson, R. A., dewaard, J. R., Houbraken, J., Lévesque, C. A., Moncalvo, J. M.,... and Hebert, P. D. (2007). Prospects for fungus identification using CO1 DNA barcodes, with Penicillium as a test case. Proceedings of the National Academy of Sciences, 104(10), 3901-3906.

Sloof, J. E. (1995). Lichens as quantitative biomonitors for atmospheric trace-element deposition, using transplants. Atmospheric Environment, 29(1), 11-20.

Stace, C. A. (1991) Plant taxonomy and biosystematics. Methods and techniques in collection, preservation and identification of lichens, Cambridge University Press, 102-128.

Upreti, D. K. (1994). Lichens: the great benefactors. Appl Bot Abst, 14(3), 64-75.

Upreti, D. K. (1995). Loss of diversity in Indian lichen flora. Environmental conservation, 22(4), 361-363.
Upreti, D. K.,and Negi, H. R. (1996). Folk use of Thamnolia vermicularis (Swartz) Ach. Lata Village of Nanda Devi Biosphere Reserve. Ethnobotany, 8, 83-6.

Upreti, D. K., and Pandev, V. (1994). Heavy metals of Antarctic lichens 1. Umbilicaria. FeddesRepertorium, 105(3- 4), 197-199.

Upreti, D. K., Divakar, P. K. and Nayaka, S. (2005). Commercial and ethnic use of lichens in India. Economic Botany, 59(3), 269.

Upreti, D. K., Joshi, Y., Divakar, P. K., Lumbsch, H. T., and Nayaka, S. (2008). Notes on some interesting lichens from. Notes, 8 , 113-116.

Vokou, D., Pirintsos, S. A., and Loppi, S. (1999). Lichens as bioindicators of temporal variations in air quality around Thessaloniki, northern Greece. Ecological Research, 14(2), 89-96.

Walker, W. F., and Doolittle, W. F. (1982). Redividing the basidiomycetes on the basis of 5S rRNA sequences. Nature, 299(5885), 723.

White, T. J., Bruns, T., Lee, S. J. W. T., and Taylor, J. (1990). Amplification and direct sequencing of fungal ribosomal RNA genes for phylogenetics In: Innis MA, Gelfand DH, Sninsky JJ, White TJ, editors. PCR protocols: a guide to methods and applications. PCR protocols: a guide to methods and applications, 315-22.

Wolseley, P. A., Moncrieff, C., and AguirreHudson, B. (1994). Lichens as indicators of environmental stability and change in the tropical forests of Thailand. Global Ecology and Biogeography Letters, 116-123.

Xu, J. (2016). Fungal DNA barcoding. Genome, 59(11), 913-932.

\section{How to cite this article:}

Sachin Singh, Mamta Arya and Shailesh Kumar Vishwakarma. 2019. Advancements in Methods Used for Identification of Lichens. Int.J.Curr.Microbiol.App.Sci. 8(08): 1450-1460. doi: https://doi.org/10.20546/ijcmas.2019.808.169 